\title{
Identification of highly transformable wheat genotypes for mass production of fertile transgenic plants
}

\author{
A. Pellegrineschi, L.M. Noguera, B. Skovmand, R.M. Brito, L. Velazquez, M.M. \\ Salgado, R. Hernandez, M. Warburton, and D. Hoisington
}

\begin{abstract}
The efficiency of wheat biolistic transformation systems strongly depends on the bombardment parameters, the condition of the donor plant, and the plant genotype chosen for the transformation process. This paper analyzes the transformation efficiency of the 129 wheat sister lines generically called 'Bobwhite', originally obtained from the cross 'Aurora'//'Kalyan'/'Bluebird 3'/'Woodpecker'. A number of factors influencing the transformation were examined, such as the ability to produce embryogenic callus, regeneration in selection medium, and overall transformation performance. Of the 129 genotypes evaluated, eight demonstrated transformation efficiencies above $60 \%$ (60 independent transgenic events per 100 immature embryos bombarded). Among the eight genotypes identified, we studied agronomic characteristics such as earliness to identify the most adaptable line(s) for different lab conditions. 'Bobwhite' SH 9826 was identified as a super-transformable wheat line.
\end{abstract}

Key words: wheat transformation, 'Bobwhite', genotype effect.

Résumé : L'efficacité de la transformation biolistique chez le blé est largement déterminée par les paramètres du bombardement, l'état de la plante-mère et le génotype employé. Cet article rapporte les résultats d'une analyse de l'efficacité de la transformation réalisée sur 129 lignées soeurs collectivement appelées 'Bobwhite' et dérivées d'un croisement 'Aurora'//'Kalyan'/'Bluebird 3'/'Woodpecker'. Plusieurs facteurs influençant la transformation ont été examinés tels que l'aptitude à produire des cals embryogènes, la régénération en milieu sélectif, et l'efficacité globale de transformation. Des 129 génotypes examinés, huit ont montré un taux de transformation dépassant $60 \%$ (60 transformants indépendants pour 100 embryons immatures bombardés). Pour ces huit génotypes, des caractères agronomiques, tels que la maturité, ont été examinés afin d'identifier les lignées les mieux adaptées aux conditions de laboratoire. Bobwhite SH 9826 a été identifiée comme étant une lignée de blé ayant une aptitude exceptionnelle à la transformation.

Mots clés : transformation du blé, 'Bobwhite', effet génotypique.

[Traduit par la Rédaction]

\section{Introduction}

The goal of various plant tissue culture techniques and transformation processes is to generate novel genetic material by the direct introduction of useful and novel genes into important crops, thus accelerating or complementing their

Received 18 May 2001. Accepted 3 December 2001.

Published on the NRC Research Press Web site at

http://genome.nrc.ca on 4 March 2002.

Corresponding Editor: J.P. Gustafson.

A. Pellegrineschi ${ }^{1}$ and D. Hoisington. Applied

Biotechnology Center, CIMMYT, Apdo Postal 6-641, 06600

Mexico, D.F., and CRC for Molecular Plant Breeding,

CIMMYT, Apdo Postal 6-641, 06600 Mexico, D.F.

L.M. Noguera1, R.M. Brito, L. Velazquez, R. Hernandez, and M. Warburton. Applied Biotechnology Center,

CIMMYT, Apdo Postal 6-641, 06600 Mexico, D.F.

B. Skovmand. Wheat Program, CIMMYT, Apdo Postal 6-641, 06600 Mexico, D.F.

${ }^{1}$ Corresponding author (e-mail: a.pellegrineschi@cgiar.org). respective breeding programs. Generally, genetic engineering programs focus on establishing reliable and straightforward plant regeneration and genetic transformation systems for the species under investigation; cloning of potentially useful genes and promoters; and generation and characterization of transgenic plants with improved agronomic characteristics. Currently the transformation system widely used in wheat is based on the particle gene-gun transfer system, in which naked DNA is physically introduced into cells by microprojectile bombardment. This process involves high-velocity acceleration of gold microprojectiles carrying foreign DNA, penetration through the cell wall and membrane by microprojectiles, and DNA delivery into plant cells (He and Lazzeri 1998).

For wheat, the prerequisite for genetic manipulation is the establishment of a routine and simple plant regeneration system through tissue culture. Various transformation and regeneration systems have been developed and tried (Altpeter et al. 1996; Barro et al. 1998; Becker et al. 1994; Fennel et al. 1996; Weeks et al. 1993), using a multitude of different wheat genotypes with a complex array of results, with the 
only common factors being the difficulty and genotype dependency of the technique (Jordan 2000; Nehra et al. 1994). One of the most responsive materials reported to be transformable by several laboratories are the sisters of the 'Bobwhite' family (Bleach 1998; Bliffeld et al. 1999). However, the name 'Bobwhite' represents a group of 129 accessions in the CIMMYT (Centro International de Milioramento de Mais y Trigo) ex situ wheat collection with different characteristics and agronomic behaviors, creating problems in the reproducibility of the experiments and confusion between wheat transformation groups. The sister lines were generated by the CIMMYT wheat program in the mid-1970s from the cross CM 33203 with the pedigree 'Aurora'// 'Kalyan'/'Bluebird 3'/'Woodpecker'; the segregating generations were selected and released in the late 1970s. These Bobwhite lines have become important germplasm in many different programs, and between 1984 and 1991, 16 of the sister lines were released as commercial cultivars in 16 locations in Africa, South America, and the Middle East (Souza et al. 1998).

The objectives of this study were $(i)$ to use the available transformation protocols and genotype data to screen all 129 'Bobwhite' accessions for their transformation ability and (ii) to identify the most transformable and responsive accessions based on their ability to regenerate, to adapt to tissue culture, and on their agronomic characteristics.

\section{Materials and Methods}

\section{Plant material}

The 129 'Bobwhite' accessions were grown in a greenhouse under controlled conditions with day temperatures of $24-28^{\circ} \mathrm{C}$ and night temperatures of $15-18^{\circ} \mathrm{C}$. To ensure continuous production of immature embryos, seeds of each variety were planted every 2-3 days. Fifteen days after heading, the immature seeds were harvested, sterilized, and a minimum of 200 immature embryos/accession were isolated for bombardment. Particular care was given to maintaining the greenhouse conditions at the same level for all the experiments, and to avoid any stress to the donor plants. Every 1520 days, routine pesticide and fertilizing treatments were applied to the donor plants. The transformation experiments were done during the dry season in central Mexico, with a maximum light intensity ranging between 700 and $1100 \mathrm{MJ} / \mathrm{m}^{2} \mathrm{~s}$.

\section{DNA plasmid vector and preparation of the microcarrier}

The plasmid used in this experiment was developed from pGEM3Zf(+), containing the selectable bar gene that confers resistance to the herbicide Basta (Hoechst, Frankfurt, Germany) under control of the maize ubiquitin promoter (Christensen et al. 1992) cloned into the HindIII site (pUbibar). Five micrograms of plasmid DNA were precipitated onto gold particles following the protocol described by Pellegrineschi et al. (2000). For each bombardment, $10 \mu \mathrm{L}$ of microparticle DNA were placed onto the macrocarrier. Bombardments were conducted at a distance of $5 \mathrm{~cm}$ from the stopping plate using a PDS 1000/He microprojectile gun (Bio-Rad, Hercules, Calif.) with 900 psi (1 psi = $6.895 \mathrm{kPa})$, according to the procedure described by Pellegrineschi et al. (2000).

Culture conditions and recovery of transformed plants

A minimum of 200 freshly isolated embryos (between 0.7 and $1.2 \mathrm{~mm}$ long) from each accession were isolated and the zygotic meristem then removed. Fifty isolated scutella per petri dish were placed on osmotic basal salt medium (Murashige and Skoog 1962) without modifications (except for the addition of $15 \% \mathrm{w} / \mathrm{v}$ maltose) for $4 \mathrm{~h}$ before bombardment. As a control for each experiment, 50 additional scutella from the same accession were transferred to the osmotic medium without bombardment. The day after bombardment, the embryos were placed on MS medium (Murashige and Skoog 1962) containing $2.5 \mathrm{mg}$ 2,4dichlorophenoxyacetic acid (2,4-D)/L, $30 \mathrm{~g}$ sucrose/L, and $8 \mathrm{~g}$ Bacto-Agar for somatic embryo induction. Between 12 and 14 days after transfer to the induction medium the induced embryos were scored for the somatic embryo formation. The induced explants were then transferred in MS medium containing $5 \mathrm{mg}$ PPT/L (DL-phosphinothricin; Sigma, St. Louis, Mo.) to a growth chamber with a photoperiod of $16 \mathrm{~h}$ light : $8 \mathrm{~h}$ dark at $25^{\circ} \mathrm{C}$ for selection. The light was provided by white cool florescent tubes (Solar) and the light intensity was $200 \mathrm{MJ} / \mathrm{m}^{2} \mathrm{~s}$. After 30 days, healthy, fully differentiated plantlets were scored and transferred to the same medium for further selection during development. Surviving green-rooted plantlets were transferred to a soil mixture and placed in the growth room. Herbicide resistance of the putative transgenic wheat plants was determined by spraying the leaves of plants at the fifth or sixth leaf stage twice with Basta $(0.3 \%$ w/v) with 7 days between applications to minimize escapes. Plants were scored as susceptible or resistant according to the degree of leaf desiccation after 7 days.

\section{Molecular analyses}

A polymerase chain reaction (PCR) was performed on plant DNA extracted from young leaves using the Nucleospin DNA Purification Kit (Clontech, Palo Alto, Calif.), following the manufacturer's protocol. All of the Basta-resistant plants that survived to tissue culture selection were analyzed by PCR for the presence of the bar gene. The pair of specific primers used were 5'-GTCTGCACCATCGTCAACC-3' (forward) and 5'-GAAGTCCAGCTGCCAGAAAC-3' (reverse). The PCRs were carried out in a total volume of $25 \mu \mathrm{L}$, consisting of $10 \mathrm{ng}$ wheat genomic DNA, $50 \mathrm{mM} \mathrm{KCl}, 10 \mathrm{mM}$ Tris- $\mathrm{HCl}(\mathrm{pH} 8.8), 3 \mathrm{mM} \mathrm{MgCl}_{2}, 0.1 \%$ Triton X-100, $0.24 \mathrm{mM}$ of each dNTP, $0.04 \mathrm{U}$ Taq DNA polymerase, and $0.16 \mu \mathrm{mol}$ of each primer. For PCR analysis of the bar gene, DNA was denatured at $94^{\circ} \mathrm{C}$ for $1 \mathrm{~min}$ (hot start), followed by 30 amplification cycles of $94^{\circ} \mathrm{C}$ for $30 \mathrm{~s}$., $64^{\circ} \mathrm{C}$ for $2 \mathrm{~min}$, and $72^{\circ} \mathrm{C}$ for $2 \mathrm{~min}$. For Southern blot analysis, the genomic DNA was isolated from $1 \mathrm{~g}$ fresh-weight leaf material using the Nucleon Phytopure Plant DNA Extraction Kit, according to the manufacturer's protocol (Amersham Life Sciences, Arlington Heights, Ill.). A 50- $\mu \mathrm{g}$ aliquot of DNA was digested overnight at $37^{\circ} \mathrm{C}$ with the appropriate restriction enzyme. The digested DNA was fractionated in a $1.0 \%$ agarose gel, transferred to a positively 
charged nylon membrane (Boehringer Mannheim, Indianapolis, Ind.) and hybridized to digoxigenin-dUTP labeled probes according to the manufacturer's instructions (Boehringer Mannheim). The DNA probe, a fragment of the bar gene, was labeled with digoxigenin-11-dUTP (Roche). Detection was achieved using the DIG Luminescent Detection Kit (Boehringer Mannheim) and the hybridization signals were visualized by exposure to Fuji X-ray film at $37^{\circ} \mathrm{C}$ for $40 \mathrm{~min}$.

\section{Analyses of the progeny}

Selfed seeds ( $T_{1}$ and $T_{2}$ generation) of the transformants were sterilized and the embryos excised. The sterile embryos were then transferred to MS medium with $5 \mathrm{mg}$ PPT/L. One week later, the embryos were scored for their survival ability. Ratios were calculated to determine if they fit expected Mendelian segregation ratios. The resistant plantlets were then transferred to a soil mixture and tested for the presence of the transgene using PCR.

\section{Statistical analyses}

The first selection of material was conducted with a minimum of 200 embryos (four bombardments with 50 scutella each; each bombardment was considered one repetition). For each experiment, the minimum, maximum, average, and standard deviation of the embryogenesis, regeneration, and transformation efficiencies were calculated. After the first selection, the best performance lines were tested again with three repetitions of 2000 embryos each (40 bombardments of 50 scutella each). Transformation efficiency was calculated as the total number of transgenic plants divided by the total number of embryos bombarded. A plant was defined as transgenic when it demonstrated resistance to the herbicide treatments and showed a positive signal for the bar gene when analyzed by PCR. The percentage of somatic embryogenesis development was calculated by dividing the total number of the embryos that differentiated (somatic embryos) by the total number of embryos bombarded. Regeneration efficiency was calculated by dividing the number of embryos that produced plantlets in selective medium by the total number of embryos bombarded.

Where the effects of treatment (bombarded scutella and control) and lines (BW) were considered to be fixed effects and replicates were considered to be random effects, the SAS macro for a generalized mixed linear model (GLINMIX) (Littell et al. 1996) was used. A binomial distribution with a logit function was considered.

\section{Results}

\section{Somatic embryo induction}

Cultures were checked for somatic embryo formation before transfer to selective medium. The effect of genotype on scutellum embryogenesis is summarized in Table 1. The majority of the 129 genotypes tested produced somatic embryos, with only 18 not reacting to the induction (Table 1). Accessions with the highest yield (nearly 100\%) of embryos producing embryogenic callus were SH 98 15, SH 9888 , SH 98 103, SH 98 108, SH 98 116, SH 98 117, SH 98 118, SH 98 119, SH 98 120, SH 98 121, and SH 98 126. All other accessions gave different efficiencies of somatic embryo formation, ranging from 0 to $96 \%$. During this stage of the transformation process, the non-bombarded embryos (controls) generally gave a more efficient formation of somatic embryos (Table 1). There were no distinct differences in stage development, with the exception of the number of scutella-differentiating somatic embryos. Generally, first globular stage somatic embryos were observed 4-5 days after the transfer, and the globular stage was usually formed directly from the scutellum. This was followed by a high frequency of repetitive somatic embryogenesis. Early globular stages were followed by the full differentiation of the somatic embryo.

\section{Transformation efficiency and selection efficiency}

The first test of the transformation efficiency was an evaluation of the regeneration performance on the selective medium. Healthy, fully differentiated embryogenic calli were scored ( 1 per embryo; Table 1$)$ as the number of regenerating calli divided by the total number of immature embryos bombarded (one regenerating callus was scored as 1). The somatic embryo germination frequency in selective medium ranged from 0 to $89 \%$. The different accessions responded in four different ways to the selection and bombardment, as follows: ( $i$ ) no regeneration; (ii) tolerant to herbicide and susceptibile to the bombardment process (e.g., lines $\mathrm{SH}$ 98 18, SH 98 88, SH 98 113); (iii) sensitive to herbicide selection, tolerant to the bombardment process, and highly regenerable (e.g., lines SH 98 26, SH 98 56); and (iv) sensitive to herbicide selection and tolerant to the bombardment process, but low regeneration (e.g., SH 98 6, SH 98 42, SH 98 46) (Table 1, Fig. 1). Transformation efficiency was calculated as the effective number of transgenic plants obtained divided by the total number of immature embryos bombarded. The most efficient lines were $\mathrm{SH} 9826$ and $\mathrm{SH}$ 9856 (Table 1). Other accessions (SH 98 15, SH 98 88, and SH 98 121) gave a higher frequency of regeneration but a lesser overall efficiency because of several escapes (defined as plants that survived the selection process but that were not transgenic). The accessions $\mathrm{SH} 98$ 26, SH 98 29, SH 98 56, SH 98 96, SH 98 97, SH 98 110, SH 98 128, and SH98129 were chosen as the best lines for transformation and were tested further as described in Material and methods; the results are shown in the Table 2.

\section{Molecular screening of transgenic plants}

Shoot tissue harvested from PPT-resistant plants was screened with PCR to verify the presence of the bar gene in the plant genome (Fig. 2). Results indicated that among the plants analyzed from all experiments, all contained the bar gene. The amplified DNA fragments (approximately $400 \mathrm{nu}-$ cleotides) from the transgenic plants were identical in size to the controls and all hybridized with the plasmid probe. Twenty independently transformed plants from each accession that successfully produced plants both resistant to the herbicide treatment and positive in the PCR analyses were analyzed for bar-gene copy number by Southern blot analysis, in which a gene copy reconstruction lane was also included. In cases where the Southern analyses indicated that there were multiple copies of the transgene (Figs. 3A and 


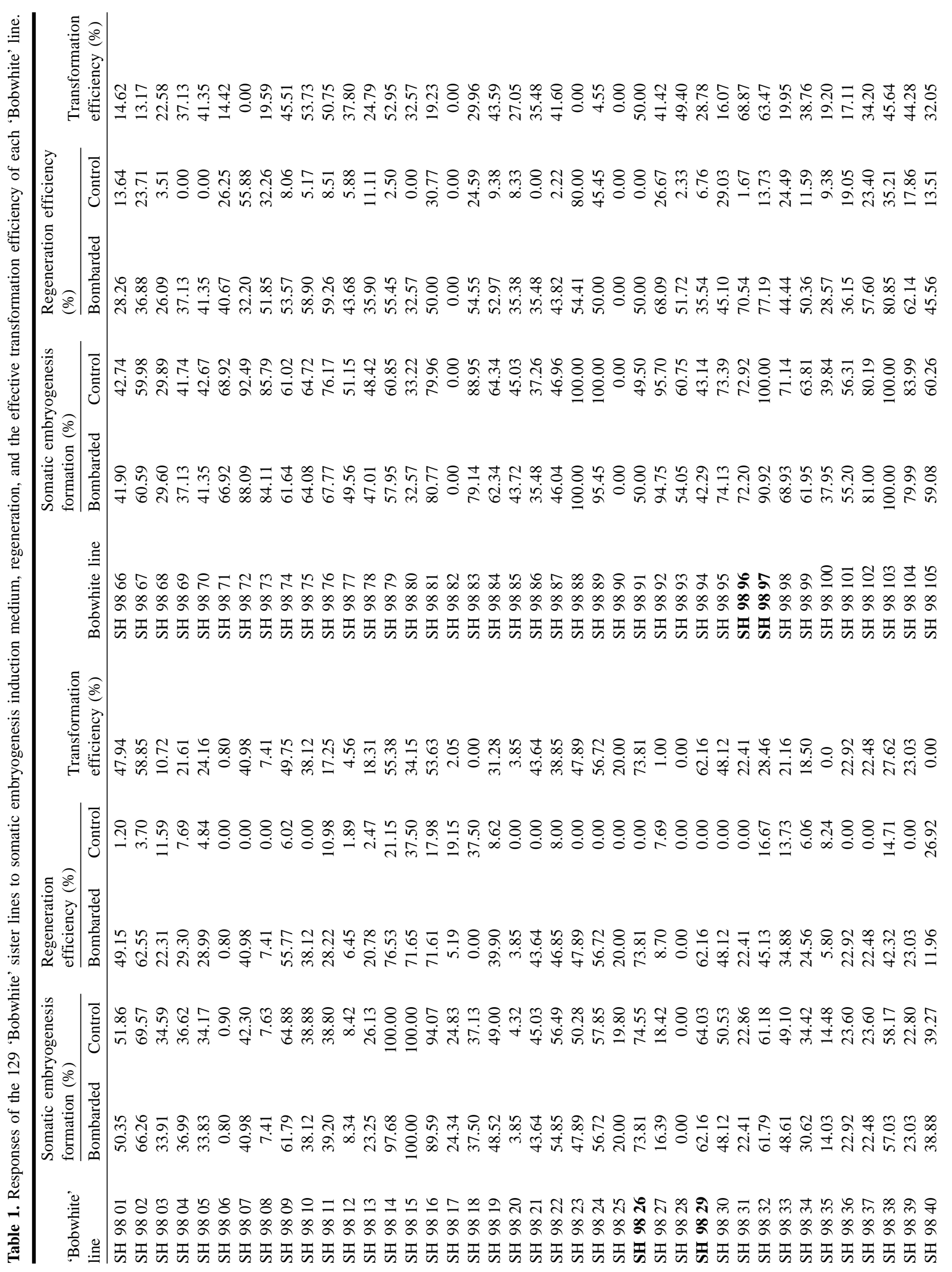


ทे ఢ으유 भे

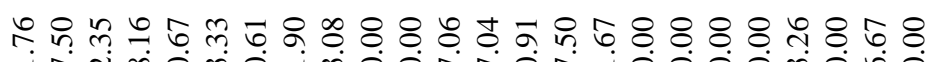
市

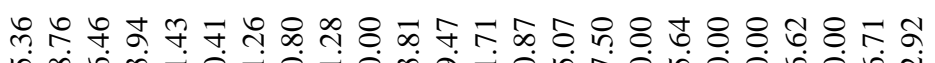

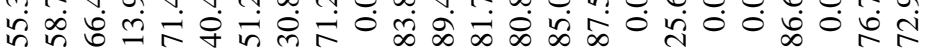

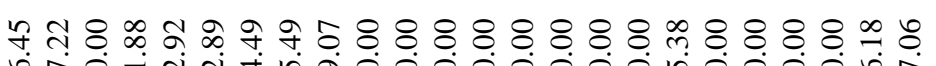

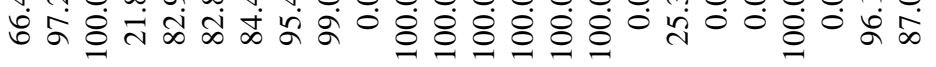

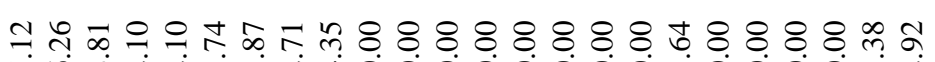
मूँ

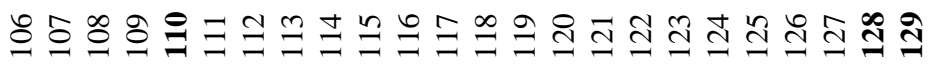
o $\infty \propto \infty \%$

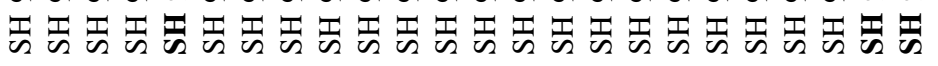

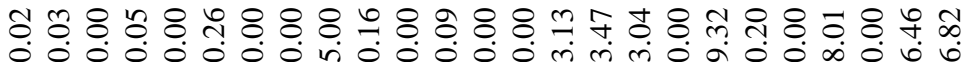

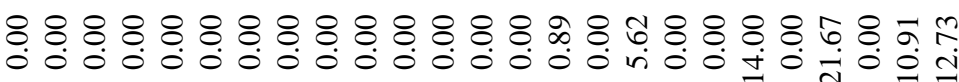

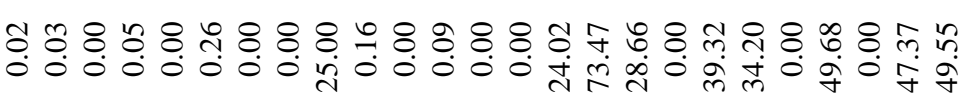

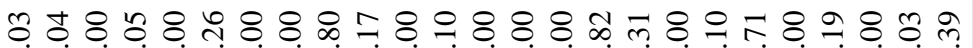

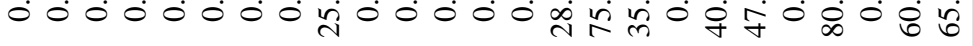

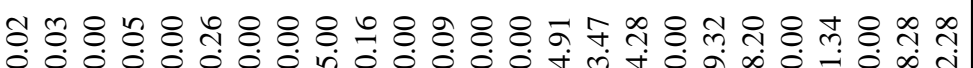

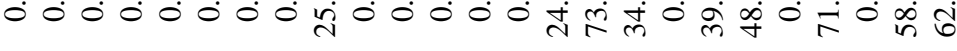

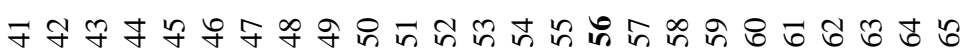
๙̊ ๙

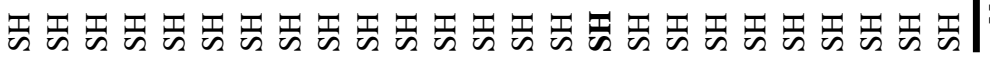


Fig. 1. Response of 'Bobwhite' line SH 9826 to the tissue culture process. (A) Somatic embryogenesis induction. (B) Plant regeneration on selective medium (5 mg PPT/L) after 15 days selection. (C) Plant regeneration on selective medium (5 mg PPT/L) after 30 days selection. Controls $\mathrm{C}$ were placed in the lower right corner in all photos.

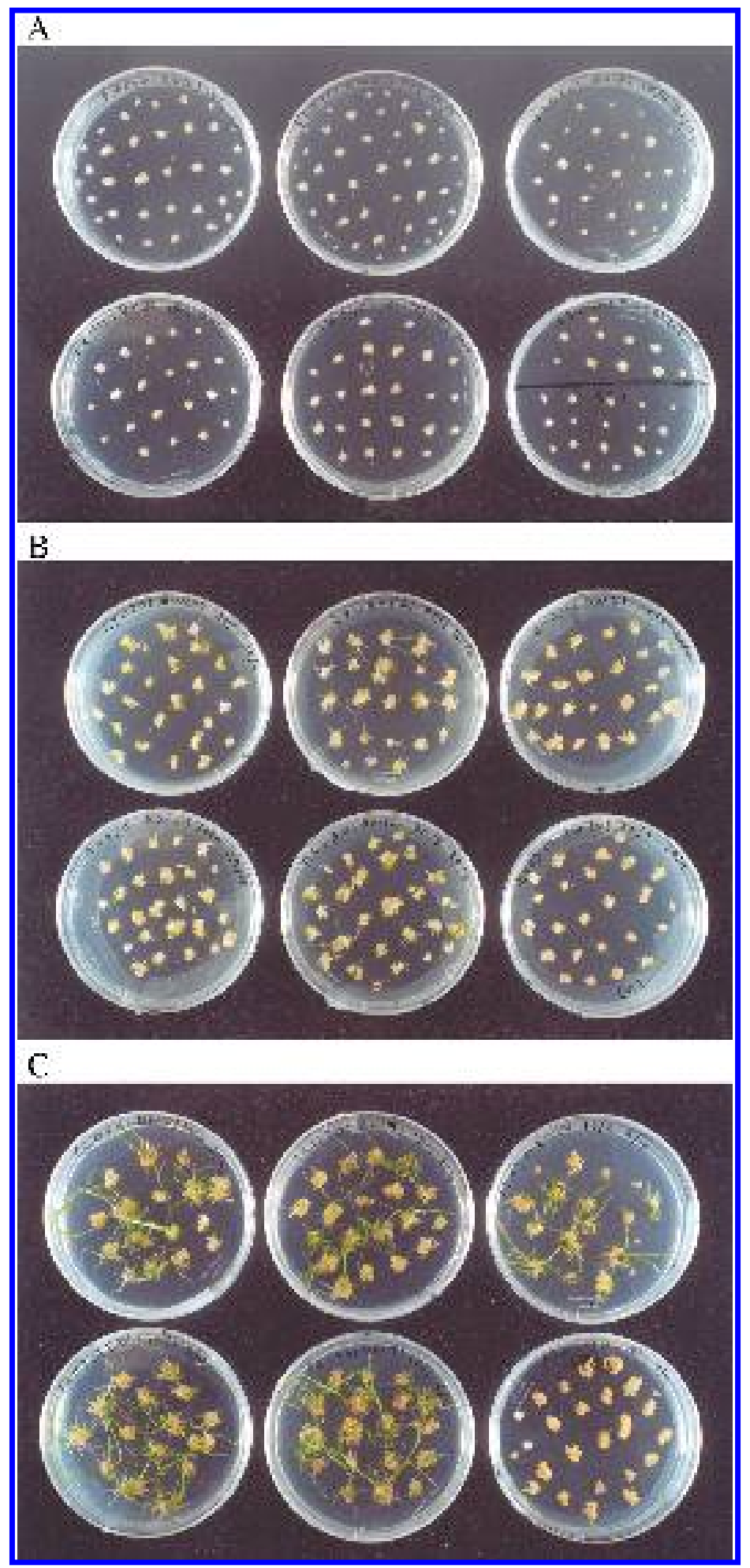

3B), all of the copies appeared to cosegregate, thus yielding progenies with either all or none of the copies. This suggests that all of the copies of the transgene were inserted at the same genetic locus. The bar transgene was inherited and expressed in the $T_{1}$ and $T_{2}$ generation lines tested (Table 3 ). In the case that more than one plant was selected from the same callus, Southern analysis was performed immediately. In the case that the band segregation patterns in the Southern blot were similar (Fig. 4), the plants were counted as one.

Fertility of transgenic wheat plants

The initial transgenic wheat plants presented a broad 
Table 2. Results of the statistical analyses of the best eight 'Bobwhite' lines for embryogenesis, regeneration in selective medium, and effective transformation efficiency.

\begin{tabular}{|c|c|c|c|c|c|}
\hline \multirow[b]{2}{*}{ 'Bobwhite' line } & \multicolumn{2}{|c|}{ Somatic embryogenesis formation (\%) } & \multicolumn{2}{|c|}{ Regeneration efficiency (\%) } & \multirow{2}{*}{$\begin{array}{l}\text { Transformation } \\
\text { efficiency }(\%)\end{array}$} \\
\hline & Bombarded & Control & Bombarded & Control & \\
\hline SH 9826 & $72.09 \pm 13.34$ & $75.35 \pm 13.39$ & $71.17 \pm 14.68$ & 0 & $70.86 \pm 14.48$ \\
\hline SH 9856 & $70.34 \pm 9.82$ & $70.14 \pm 5.98$ & $70.34 \pm 9.83$ & 0.00 & $69.02 \pm 6.94$ \\
\hline SH 9896 & $69.17 \pm 9.92$ & $69.97 \pm 4.73$ & $69.17 \pm 9.93$ & $2.43 \pm 1.55$ & $66.96 \pm 6.14$ \\
\hline SH 9897 & $90.96 \pm 5.95$ & $93.33 \pm 4.92$ & $76.63 \pm 9.02$ & $13.98 \pm 4.54$ & $66.96 \pm 4.53$ \\
\hline SH 98129 & $80.55 \pm 7.01$ & $85.59 \pm 6.11$ & $71.82 \pm 9.61$ & $10.08 \pm 3.58$ & $60.04 \pm 9.61$ \\
\hline
\end{tabular}

Note: The data were pooled from three repetitions with more than 2000 embryos/transformation experiment.

Fig. 2. PCR analyses of some of the transformants of the line SH 98 26. DNA was extracted from leaves as described in Materials and methods. Each lane represents an independent event. Plants 10 and 16 did not survive the Basta treatment.

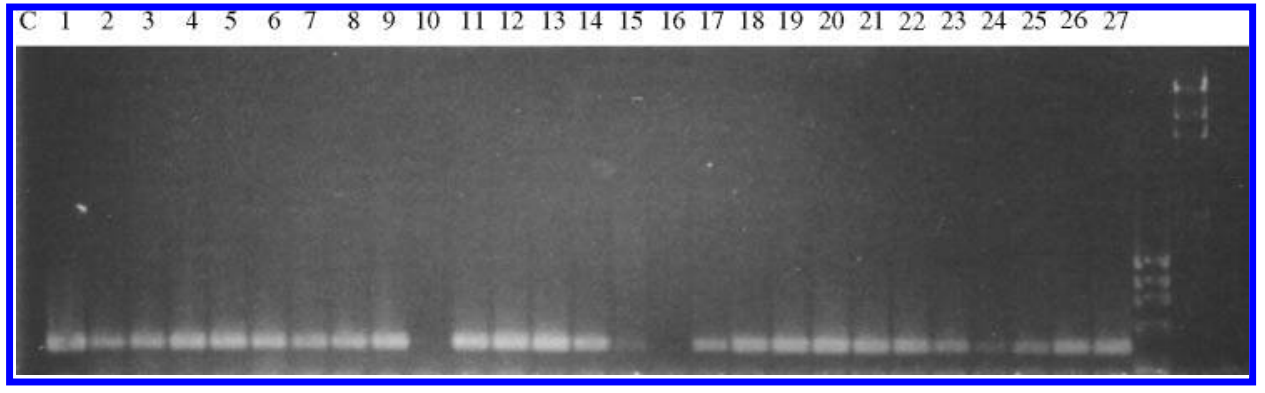

range of fertility, although most were at least partially fertile. Only a few of the plants were completely sterile. Fertility was usually restored in the subsequent generations, indicating that partial sterility observed at the $\mathrm{T}_{0}$ generation was not an inherited trait in most cases.

\section{Inheritance of the marker gene}

The selected progeny were evaluated again for resistance to PPT. Resistant and sensitive seedlings were clearly distinguishable after spraying with $0.3 \%$ Basta. A segregation ratio of 3:1 was observed for 500 of 600 independent transgenic events tested. Twenty lines (randomly taken) were studied for inheritance of the transgenes as shown in the Table 3. The Basta-resistant progeny of the plants that gave segregation ratios of $3: 1$ or 1:0 were analyzed by PCR and Southern hybridization. All of the Basta-resistant progeny contained bands that hybridized with the probe for the bar gene, whereas none of the sensitive progeny hybridized to the probe and thus may have been segregants or escapes (data not shown).

\section{Statistical analyses results}

The results of the minimum, maximum, average, and standard deviation of the embryogenesis, regeneration, and transformation efficiencies are shown Tables 1 and 3. Results of the analysis of the eight best 'Bobwhite' accessions showed highly significant differences between bombarded scutella and controls $(P<0.05)$. This analysis was done excluding the 'Bobwhite' line $\times$ treatment interaction because of an imbalance in some levels of the main effects of the 'Bobwhite' line that was not estimable. The main effects of treatment on bombarded scutella versus control were highly significant with an estimated proportion of regeneration of
0.72 vs. 0.07 . There were significant differences among the top eight 'Bobwhite' lines. Line SH 98128 showed the highest proportion of regenerated plants (0.48) and line SH 9829 showed the lowest proportion (0.19).

\section{Discussion}

The goal of many genetic engineering efforts is to contribute to sustained production of affordable and high-quality food by introducing novel characteristics into plant varieties. For CIMMYT, the aim is to work on problems that affect a large number of resource-poor farmers in developing countries and to apply biotechnology in such a way that it augments conventional breeding efforts. This goal can be reached only if the novel characteristics introduced into crops such as wheat are used by the breeding programs. In turn, these novel characteristics will advance in breeding only if they are stable and effective. This currently requires the production of a collection of transgenic plants for each novel trait to permit the selection of the most appropriate individuals for the breeding program. Initially, this requires an efficient gene transfer protocol.

The efficiency of a wheat biolistic transformation system strongly depends on the bombardment parameters, the condition of the donor plant, and the plant genotype chosen for the transformation process (Witrzens et al. 1998). A highly responsive wheat genotype is advantageous because it can enhance the efficiency of biolistic transformation and may be useful in other protocols such as Agrobacterium-mediated transformation. To identify highly responsive genotypes, it is necessary to optimize and standardize tissue-culture conditions and transformation efficiency (Pellegrineschi et al. 
Fig. 3. Southern blot analysis of regenerated $\mathrm{T}_{0}$ plants from the line SH 9826 after SmaI restriction digest of the plasmid (unique site on Ubibar plasmid). The DNA was digested with SmaI and then probed with the digoxygenin-labeled bar gene. Lanes 1 and 20 in A and lanes 1 and 14 in B contain a $\lambda$ ladder. Lanes 2 and 3 in both $\mathrm{A}$ and B are the copy number references (copy numbers 10 and 5 , respectively). Lanes 5-19 in A and lanes 7-12 in B are from Basta-resistant plants. Controls are in lanes 4-6 in 3B.

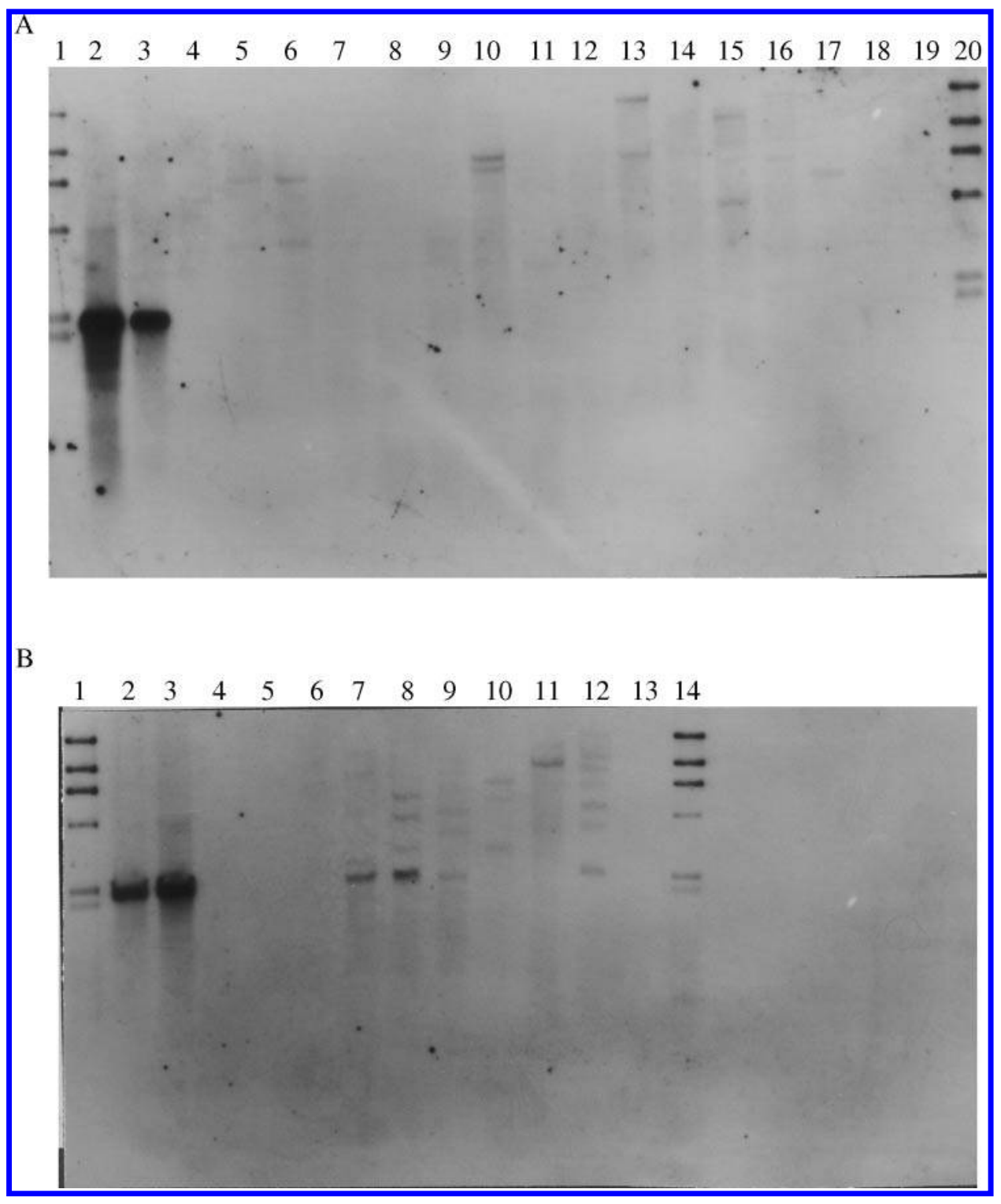

2000), as well as identify the specific physiological conditions of the starting material for transformation.

For screening the material, the standardization of the physiological status of the donor plants was one of the most critical factors for comparing the transformation abilities among the 'Bobwhite' accessions. After testing under various conditions (data not shown), a uniform non-stressed growth environment was selected for the optimal growth of the donor plants.

The choice of the zygotic embryo development stage was another important factor. Various development stages were screened for their response to the transformation process. The dimension of the embryo ( $1 \mathrm{~mm}$ on the longest side) was taken as standard in all accessions regardless of the number of days after pollination because at this developmental stage the scutella are more responsive to the tissue culture (e.g., rapid bevelopment of embryogenic callus). In the transformation experiments, the accessions SH 9826 and SH 9856 were slightly more efficient than the other accessions, with an overall efficiency of more than $70 \%$, although their ability to differentiate somatic embryos was less than other accessions (Table 1). The performance of these accessions could be explained by their high sensitivity to herbicide selection (non-transformed controls were not able to produce plants under selection conditions), as compared with accessions such as SH 98 121, in which nearly 100\% of the immature embryos produced somatic embryos. However, the controls for SH 98121 also produced plantlets during the selection process, thus increasing the number of escapes.

Between the two high performing varieties, we determined the variety SH 9826 to be super transformable because of its early maturity (under the right conditions, this 
Table 3. Segregation of the Basta-resistant phenotype in $T_{1}$ and $T_{2}$ generation on randomly selected transgenic plants.

\begin{tabular}{|c|c|c|c|c|c|c|c|c|}
\hline \multirow[b]{2}{*}{ Event No. } & \multicolumn{4}{|c|}{$\mathrm{T}_{1}$ plant tested for herbicide spray } & \multicolumn{4}{|c|}{$\mathrm{T}_{2}$ plant tested for herbicide spay } \\
\hline & Resistant & Sensitive & $\mathrm{R}: \mathrm{S}$ & $\chi^{2}$ & Resistant & Sensitive & $\mathrm{R}: \mathrm{S}$ & $\chi^{2}$ \\
\hline 5508 & 20 & 11 & $3: 1$ & 0.2555 & 25 & 5 & $3: 1$ & 0.1563 \\
\hline 5679 & 12 & 23 & SD & 4.3513 & 34 & 8 & $3: 1$ & 0.1116 \\
\hline 5971 & 32 & 5 & $3: 1$ & 0.3661 & 22 & 6 & $3: 1$ & 0.0268 \\
\hline 5993 & 50 & 9 & $3: 1$ & 0.4203 & 26 & 5 & $3: 1$ & 0.183 \\
\hline 6035 & 19 & 5 & $3: 1$ & 0.0313 & 21 & 3 & $3: 1$ & 0.2813 \\
\hline 6067 & 34 & 0 & $1: 0$ & 0 & 20 & 0 & $1: 0$ & 0 \\
\hline 6070 & 30 & 8 & $3: 1$ & 0.0444 & 25 & 6 & $3: 1$ & 0.0741 \\
\hline 6074 & 7 & 6 & $3: 1$ & 0.4363 & 23 & 5 & $3: 1$ & 0.1071 \\
\hline 6160 & 26 & 19 & SD & 1.001 & 45 & 12 & $3: 1$ & 0.0666 \\
\hline 6255 & 12 & 10 & SD & 0.6903 & 32 & 8 & $3: 1$ & 0.075 \\
\hline 6256 & 10 & 32 & SD & 8.2545 & 16 & 4 & $3: 1$ & 0.0375 \\
\hline 6940 & 5 & 13 & SD & 3.0104 & 20 & 8 & $3: 1$ & 0.0268 \\
\hline 6942 & 4 & 15 & SD & 4.1472 & 22 & 7 & $3: 1$ & 0.0016 \\
\hline
\end{tabular}

Note: Mendelian segregation of this trait was observed in 12 lines on the $\mathrm{T}_{1}$ generation and in all 20 in the $\mathrm{T}_{2}$ generation. $\mathrm{SD}$, substantial deviation from the expected segregation ratio

Fig. 4. Southern blot analysis of $\mathrm{T}_{0}$ plants regenerated from the same callus. The DNA was digested with $S m a \mathrm{I}$ and then probed with the digoxygenin-labeled bar gene. Lane 1, $\lambda$ molecular weight ladder; lanes 2 and 3, 10 and 5 copies of the plasmid, respectively; lane 4, non-transgenic plant control; lanes 5-10, plantlets derived from the same callus (plants 5, 7, and 8 were considered a single event, plants 6 and 9 were considered to be escapes, and plant 10 was considered an independent event); lanes 12-16, plants derived from one callus; lanes 17 and 18 , non transgenic controls.

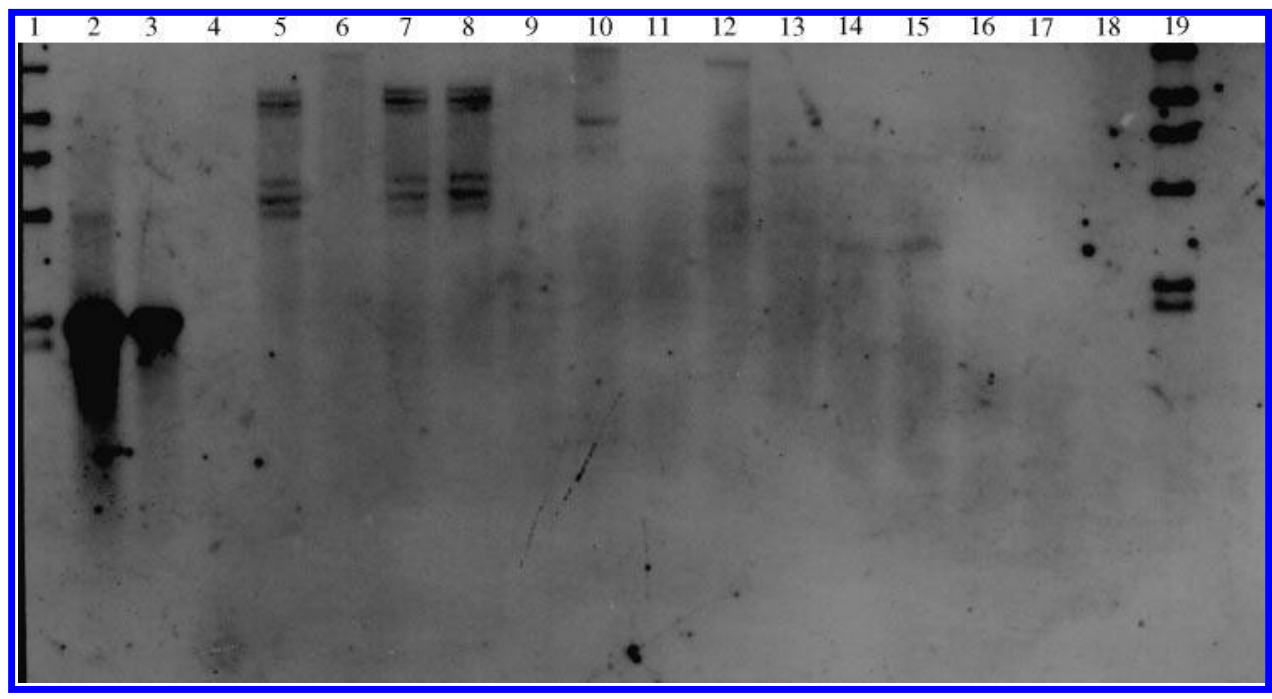

variety could produce 4 generations in a year), because it does not have the T1BL.1RS translocation, and because it could be suitable as a parent for breeding programs. Genetic analyses of the $T_{1}$ and $T_{2}$ progeny provided conclusive evidence of the incorporation of the bar transgene into wheat chromosomes. The bar gene, in the majority of cases, was inherited with a Mendelian ratio of 3:1. However, in some progeny Basta resistance was expressed in the $\mathrm{T}_{1}$ generation with an unusual pattern of segregation, but the $T_{2}$ generated from Basta resistant $T_{1}$ plants segregated in the expected Mendelian ratio (3:1 or 1:0 for homozygous plants).

The ability of the particle gun to consistently transform wheat has been previously reported (Lonsdale et al. 1998; Vasil et al. 1992; Witrzens et al. 1998). However, it has been noted that cereal transformation is still difficult because of the number of parameters involved in the technique (Lonsdale et al. 1998; Vasil et al. 1992; Lörz et al. 1996; Uze et al. 1999; Vasil et al. 1993). In deference to this constraint, we 
attempted to reduce the number of parameters, particularly the time in tissue culture, and modify the selection pressure.

In conclusion, we have identified a 'Bobwhite' accession (SH 98 26) that is highly efficient for the recovery of transgenic plants. With this variety, we were able to achieve a transformation efficiency that consistently exceeded $70 \%$, based on the average of several transformation experiments. We believe that the use of this variety will enable the constant production of transgenic wheat plants and allow the latest discoveries in biotechnology (genes, promoters, new possibilities of modifying metabolic pathways) to be routinely applied. Further research is in progress to reduce the complexity of the insertions thus producing transformed plants suitable for wheat breeding programs.

\section{Acknowledgements}

This research is funded in part by the Australian Cooperative Research Center for Molecular Plant Breeding, of which CIMMYT is a core participant. The 'Bobwhite' family was developed by Dr S. Rajaram and is stored in the CIMMYT germplasm bank, as in-trust material under an FAO (Food and Agriculture Organization of the United Nations) / CIMMYT agreement.

\section{References}

-Altpeter, F., Vasil, V., Srivastava, V., Stoger, E., and Vasil, I.K. 1996 Accelerated production of transgenic wheat (Triticum aestivum L.) plants. Plant Cell Rep. 16: 12-17.

$\checkmark$ Barro, F., Cannell, M.E., Lazzeri, P.A., and Barcelo, P. 1998. The influence of auxins on transformation of wheat and tritordeum and analysis of transgene integration patterns in transformants. Theor. Appl. Genet. 97: 684-695.

Christensen, A.H., Sharrock, R.A., and Quail, P.H. 1992. Maize polyubiquitin genes: genes, structure, thermal perturbation of expression and transcript splicing, and promoter activity following transfer to protoplast by electroporation. Plant Mol. Biol. 18: $675-689$.

He, G.Y., and Lazzeri, P. A. 1998. Analysis and optimisation of DNA delivery into wheat scutellum and Tritordeum inflorescence explants by tissue electroporation. Plant Cell Rep. 18: 64-70.
Littell, R.A., Milliken, G.A., Stroup, W.W., and Wolfinger, R.D. 1996. SAS system for mixed models. SAS Institute Inc., Cary, N.C.

-Lonsdale, D.M., Lindup, S., Moisan, L.J., and Harvey, A.J. 1998. Using firefly luciferase to identify the transition from transient to stable expression in bombarded wheat scutellar tissue. Physiol. Plant. 102: 447-453.

Lörz, H., Becker, D., and Lutticke, S. 1996. Molecular wheat breeding by direct gene transfer in wheat: prospects for global improvement. In Proceedings of the 5th International Wheat Conference, Ankara, Turkey. Edited by H. J. Braun, F. Altay, W.E. Kronstad, S.P.S. Beniwal, and A. McNab, Kluwer Academic Publishers, Dordrecht, The Netherlands. pp. 285-289.

Murashige, T., and Skoog, F. 1962. A revised medium for rapid growth and bioassays with tobacco tissue cultures. Physiol. Plant. 15: 473-497.

Pellegrineschi, A., Fennell, S., McLean, S., Brito, R.M., Velazquez, L., Salgado, M., Olivares, J.J., Hernandez, R., and Hoisington, D. 2000. Routine transformation system for use with CIMMYT wheat varieties. In Application of biotechnologies to wheat breeding. Proceedings of a conference at $\mathrm{La}$ Estanzuela, Uruguay, 19-20 November 1998, Montevideo, Uruguay. Edited by M. Koholi and M. Francis. pp. 111-120.

-Souza, E., Fox, P.N., and Scovmand, B. 1998. Parentage analysis of international spring wheat yield nurseries. Crop Sci. 38: 337-341.

-Uze, M., Potrykus, I., and Sautter, C. 1999 Single-stranded DNA in the genetic transformation of wheat (Triticum aestivum L.): transformation frequency and integration pattern. Theor. Appl. Genet. 99: 487-495.

Vasil, V., Castillo, A.M., Fromm, M.E., and Vasil, I.K. 1992. Herbicide resistant fertile transgenic wheat plants obtained by microprojectile bombardment of regenerable embryogenic callus. BioTechnology, 10: 667-674.

Vasil, V., Srivastava, V., Castillo, A.M., Fromm, M.E., and Vasil, I.K. 1993. Rapid production of transgenic wheat plants by direct bombardment of cultured immature embryos. BioTechnology, 11: $1553-1558$.

-Weeks, J.T., Anderson, O.D., and Blechl, A.E. 1993. Rapid production of multiple independent lines of fertile transgenic wheat (Triticum aestivum). Plant Physiol. 102: 1077-1084.

Witrzens, B., Brettell, R.I.S., Murray, F.R., McElroy, D., Yi, L.Z., and Dennis, E.S. 1998. Comparison of three selectable marker genes for transformation of wheat by microprojectile bombardment. Aust. J. Plant Physiol. 25: 39-44. 


\section{This article has been cited by:}

1. Joanna M. Risk, Liselotte L. Selter, Simon G. Krattinger, Libby A. Viccars, Terese M. Richardson, Gabriele Buesing, Gerhard Herren, Evans S. Lagudah, Beat Keller. 2012. Functional variability of the Lr34 durable resistance gene in transgenic wheat. Plant Biotechnology Journal no-no. [CrossRef]

2. Jiarui Li, Xingguo Ye, Baoyan An, Lipu Du, Huijun Xu. 2012. Genetic transformation of wheat: current status and future prospects. Plant Biotechnology Reports . [CrossRef]

3. C. Saint Pierre, J. L. Crossa, D. Bonnett, K. Yamaguchi-Shinozaki, M. P. Reynolds. 2012. Phenotyping transgenic wheat for drought resistance. Journal of Experimental Botany 63:5, 1799. [CrossRef]

4. Susanne Brunner, Daniel Stirnweis, Carolina Diaz Quijano, Gabriele Buesing, Gerhard Herren, Francis Parlange, Pierre Barret, Caroline Tassy, Christof Sautter, Michael Winzeler, Beat Keller. 2011. Transgenic Pm3 multilines of wheat show increased powdery mildew resistance in the field. Plant Biotechnology Journal no-no. [CrossRef]

5. Susanne Brunner, Severine Hurni, Gerhard Herren, Olena Kalinina, Simone von Burg, Simon L. Zeller, Bernhard Schmid, Michael Winzeler, Beat Keller. 2011. Transgenic Pm3b wheat lines show resistance to powdery mildew in the field. Plant Biotechnology Journal 9:8, 897-910. [CrossRef]

6. Muhammad Fahim, Anthony A. Millar, Craig C. Wood, Philip J. Larkin. 2011. Resistance to Wheat streak mosaic virus generated by expression of an artificial polycistronic microRNA in wheat. Plant Biotechnology Journal no-no. [CrossRef]

7. G.-P. Xue, H. M. Way, T. Richardson, J. Drenth, P. A. Joyce, C. L. McIntyre. 2011. Overexpression of TaNAC69 Leads to Enhanced Transcript Levels of Stress Up-Regulated Genes and Dehydration Tolerance in Bread Wheat. Molecular Plant 4:4, 697-712. [CrossRef]

8. Troy J. Stephenson, C. Lynne McIntyre, Christopher Collet, Gang-Ping Xue. 2011. TaNF-YB3 is involved in the regulation of photosynthesis genes in Triticum aestivum. Functional \& Integrative Genomics 11:2, 327-340. [CrossRef]

9. Xing-Guo YE, Ming CHEN, Li-Pu DU, Hui-Jun XU. 2011. Description and evaluation of transformation approaches used in wheat. Hereditas (Beijing) 33:5, 422-430. [CrossRef]

10. Li-li TAO, Gui-xiang YIN, Li-pu DU, Zheng-yuan SHI, Mao-yun SHE, Hui-jun XU, Xing-guo YE. 2011. Improvement of Plant Regeneration from Immature Embryos of Wheat Infected by Agrobacterium tumefaciens. Agricultural Sciences in China 10:3, 317-326. [CrossRef]

11. Muhammad Fahim, Ligia Ayala-Navarrete, Anthony A. Millar, Philip J. Larkin. 2010. Hairpin RNA derived from viral NIa gene confers immunity to wheat streak mosaic virus infection in transgenic wheat plants. Plant Biotechnology Journal 8:7, 821-834. [CrossRef]

12. J. F. Pereira, G. Zhou, E. Delhaize, T. Richardson, M. Zhou, P. R. Ryan. 2010. Engineering greater aluminium resistance in wheat by over-expressing TaALMT1. Annals of Botany 106:1, 205-214. [CrossRef]

13. Simone von Burg, Christine B. Müller, Jörg Romeis. 2010. Transgenic disease-resistant wheat does not affect the clonal performance of the aphid Metopolophium dirhodum Walker. Basic and Applied Ecology 11:3, 257-263. [CrossRef]

14. P. Guo, M. Baum, S. Grando, S. Ceccarelli, G. Bai, R. Li, M. von Korff, R. K. Varshney, A. Graner, J. Valkoun. 2009. Differentially expressed genes between drought-tolerant and drought-sensitive barley genotypes in response to drought stress during the reproductive stage. Journal of Experimental Botany 60:12, 3531-3544. [CrossRef]

15. Janice M. Zale, S. Agarwal, S. Loar, C. M. Steber. 2009. Evidence for stable transformation of wheat by floral dip in Agrobacterium tumefaciens. Plant Cell Reports 28:6, 903-913. [CrossRef]

16. Sanae Shimada, Taiichi Ogawa, Satoshi Kitagawa, Takayuki Suzuki, Chihiro Ikari, Naoki Shitsukawa, Tomoko Abe, Hiroyuki Kawahigashi, Rie Kikuchi, Hirokazu Handa, Koji Murai. 2009. A genetic network of flowering-time genes in wheat leaves, in which an APETALA1 / FRUITFULL -like gene, VRN1, is upstream of FLOWERING LOCUS T. The Plant Journal 58:4, 668-681. [CrossRef]

17. Paramjit Khurana, Harsh Chauhan, Shreenivas A. DesaiWheat . [CrossRef]

18. Agnelo Furtado, Robert J. Henry, Alessandro Pellegrineschi. 2009. Analysis of promoters in transgenic barley and wheat. Plant Biotechnology Journal 7:3, 240-253. [CrossRef]

19. Scott A. Boden, Peter Langridge, German Spangenberg, Jason A. Able. 2009. TaASY1 promotes homologous chromosome interactions and is affected by deletion of Ph1. The Plant Journal 57:3, 487-497. [CrossRef]

20. V. S. Fadeev, H. R. Shimshilashvili, A. K. Gaponenko. 2008. Induction, regeneration, and biolistic sensitivities of different genotypes of common wheat (Triticum aestivum L.). Russian Journal of Genetics 44:9, 1096-1104. [CrossRef] 
21. Taiichi Ogawa, Hiroyuki Kawahigashi, Seiichi Toki, Hirokazu Handa. 2008. Efficient transformation of wheat by using a mutated rice acetolactate synthase gene as a selectable marker. Plant Cell Reports 27:8, 1325-1331. [CrossRef]

22. Huixia Wu, Angela Doherty, Huw D. Jones. 2008. Efficient and rapid Agrobacterium-mediated genetic transformation of durum wheat (Triticum turgidum L. var. durum) using additional virulence genes. Transgenic Research 17:3, 425-436. [CrossRef]

23. S.J. Yue, H. Li, Y.W. Li, Y.F. Zhu, J.K. Guo, Y.J. Liu, Y. Chen, X. Jia. 2008. Generation of transgenic wheat lines with altered expression levels of 1Dx5 high-molecular weight glutenin subunit by RNA interference. Journal of Cereal Science 47:2, 153-161. [CrossRef]

24. Giuseppe Dionisio, Preben B. Holm, Henrik Brinch-Pedersen. 2007. Wheat (Triticum aestivum L.) and barley (Hordeum vulgare L.) multiple inositol polyphosphate phosphatases (MINPPs) are phytases expressed during grain filling and germination. Plant Biotechnology Journal 5:2, 325-338. [CrossRef]

25. S. Travella, S. M. Ross, J. Harden, C. Everett, J. W. Snape, W. A. Harwood. 2005. A comparison of transgenic barley lines produced by particle bombardment and Agrobacterium-mediated techniques. Plant Cell Reports 23:12, 780-789. [CrossRef]

26. Alessandro Pellegrineschi, Matthew Reynolds, Mario Pacheco, Rosa Maria Brito, Rosaura Almeraya, Kazuko YamaguchiShinozaki, and David Hoisington. 2004. Stress-induced expression in wheat of the Arabidopsis thaliana DREB1A gene delays water stress symptoms under greenhouse conditions. Genome 47:3, 493-500. [Abstract] [PDF] [PDF Plus] 